\title{
Getting Organized for Action: Governance Structure Models for Statewide OER Projects
}

\author{
STEVEN J. Bell
}

\begin{abstract}
When academic librarians began to address the high cost of textbooks a decade ago, they typically created textbook affordability programs tailored to the needs of their own institutions. Acting independently allowed for fast implementation and progress, but the downside of going it alone is the potential lack of sustainability. While colleges and universities continue to develop local programs, the predominant trend more recently is the statewide open educational resources initiative. This article reports the findings of a survey of these state initiatives to learn more about their governance structures, as no one model has emerged. This information can benefit existing and future statewide initiatives to optimally structure their governance model for productivity, inclusiveness, and sustainability.
\end{abstract}

\section{INTRODUCTION}

There is a proverb of uncertain origin that goes, "To go fast go alone, but to go far go together." These words reflect the progression of the open educational resources (OER) and textbook affordability movement among American colleges and universities. Led by their academic librarians, dozens of institutions have implemented, to some degree, an initiative to encourage and support educators to replace more costly textbooks with no- or low-cost learning materials over the past decade. When these initiatives were in an earlier, more experimental stage, with librarians working independently or with campus colleagues to develop their alternative textbook programs, they were typically limited to single institutions. While these early adopters engaged with each other in informal networks, they gave little or no thought to tackling the problem of textbook affordability in formalized coalitions. 
Two early adopter examples, Temple University and the University of Massachusetts-Amherst, established a model for what are now known as faculty incentive programs, in which the academic library manages a fund to provide awards to faculty who agree to flip their course from a commercial textbook to no-cost learning materials (Bell 2012; Allen, Bell, and Billings 2014). These and similar programs operated entirely independently from each other despite their similar structure and intention (Billings et al. 2012). Jensen and West (2015) identified ways in which institutional libraries could lead the development of initiatives on their campuses. In their review of academic library support for OER, Reed and Jahre point almost exclusively to individual efforts by academic libraries to advance textbook affordability. Writing in 2019, as more statewide initiatives were emerging, they stated that "libraries that can make themselves central partners in collaborative institution- or state-wide OER programs can ensure that they will be part of the long term conversation around OER and maintain their role as the information experts on campus" (241). This demonstrates that, over time, as individual academic library initiatives evolved, there was a growing recognition that statewide programs offer potential as a reliable route to sustainable affordability efforts.

One early effort to create a more formal network of OER librarian advocates, the Open Textbook Network (OTN; which in 2020 changed its name to the Open Education Network), brought these individual program leaders together in 2014 to discuss strategies to effectively promote faculty adoption of open learning content. It was not until the second annual meeting, known as the Open Textbook Network Summer Institute, that some newcomers to the OER scene made an appearance. Representatives from a few of the early statewide OER projects, having joined the OTN as institutional members, participated in the program. Although their approaches to textbook affordability were different from the individual institutional members, they demonstrated a capacity to achieve widespread impact by engaging many academic libraries in their initiative. Strength in numbers could clearly prove effective in obtaining state funding and support. In addition, the traditional library consortia that were the organizing bodies for the statewide groups brought professional administration and management to the effort. If it was not immediately apparent then, individual members could see advantages that statewide approaches could yield.

When the author proposed to their state's academic library consortium that it should engage with member libraries to initiate a Pennsylvania statewide textbook affordability project, the response was enthusiastic and affirmative. An initial set of conversations between consortium leaders and library deans and directors led to a firm commitment to establish a statewide initiative in Pennsylvania. Over a six-month period, a small group of 
state leaders already leading institutional OER initiatives or interested in doing more to achieve textbook affordability met to start the organization process. The one simple challenge was how to organize the initiative. There was no blueprint for how to structure it. This left the newly formed steering committee with little guidance on which organizing structure might work best.

Discovering this dearth of information on the organizational structure of existing statewide OER initiatives led the author on a journey to investigate how and why formal statewide initiatives chose a particular governance structure. Was there a particular model emerging as a favored structure? What mix of librarians and consortium staff or government officials constituted the governing body? How were these structures organizing to conduct work such as education, awareness building, data collection, and other functions? The primary source of information for this research is the current consortium members of the OTN. These organizations have formal structures in place for governing their projects. These structures can vary from small executive groups to more complex hierarchical structures. Both consortium directors and governance participants responded to questions about their motivation for and satisfaction with participating in these initiatives. Secondarily, other state leaders for OER movements were contacted to gather information about the structure of less formal approaches to statewide initiatives. While there are also university systems that operate collaborative statewide OER networks, such as the State University of New York or California State University systems, this article focuses on statewide efforts that enlist the colleges and universities of many different institutions to work in statewide coalitions, in which some or all members of a state university system may participate.

This communication led to the collection of information about and analysis of the governance structures of existing statewide OER initiatives. This article shares information about who participates in these organizations, the nature of their experience, and what approaches are used to conduct the work of the initiative for education, outreach, and advocacy. The overarching goal of this research is to identify organizational structures and recommendations for use by existing and future statewide OER initiative projects to optimize their work to promote OER adoption and other textbook affordability measures in higher education.

\section{State Initiatives ON THE Rise}

In the years since that OTN meeting where three states, Louisiana, Virginia, and Illinois, were represented, college and university libraries in additional states have organized to tackle the challenge of textbook affordability. Perhaps the best indicator is the increase in number of state members of the OTN as presented on their 2019 members list. To date, those 
states represented include Colorado, Florida, Idaho, Illinois, Indiana, Louisiana, Minnesota, Missouri, Montana, New Jersey, Ohio, Pennsylvania, South Carolina, Utah, Virginia, and Washington. Other states that are not members of OTN, such as Massachusetts and Michigan, are forming statewide approaches under the auspices of their states' departments of higher education. Among the advantages that academic librarians could realize in partnering with their statewide consortium are:

- Increase funding opportunities from state governments

- Centralize education and training for statewide reach

- Enable underresourced libraries to participate more fully

- Access to the resources of the OTN (if acquiring membership)

- Leverage faculty and student partners for greater advocacy power

The primary disadvantage of the statewide approach to textbook affordability, as with any large-scale effort, is determining how each participant will engage with the initiative and have an opportunity to equally participate and influence decision making. In the majority of cases, the single-campus initiative has the distinct advantage of nimbleness; it has the potential to start and progress more quickly as there is no need to accommodate the differences of large/small, public/private, urban/rural, two-year/four-year institutions that will come together under the statewide umbrella. The success of any statewide initiative, compared to an individual campus one, is largely dependent on the way it chooses to structurally organize and offer opportunities for engagement and governance across the spectrum of participating institutions.

Leaders of early statewide programs had few specific OER models to guide how best to organize governing their statewide projects. A common arrangement for other types of initiatives, such as a statewide digitization project, was for librarians to align with their state library consortium staff. Library consortia were natural partners, providing expertise at operationalizing and managing collaborative library projects and applying it to emerging statewide OER initiatives. To advance their efforts, formal statewide initiatives began to join the OTN. This effort enabled all members of the consortium, regardless of local resources, to take advantage of training and development for librarians, outreach to faculty, and advocating in state legislatures for OER funding and support. An initial examination of these early leaders revealed little or no consistency in their governance models. While states with no formal or informal statewide initiative remain in the majority, it is clear that more states are on a trajectory to develop an initiative in the coming years. That trajectory raises the question of how any new statewide initiative should organize its governing structure to optimize the resources of consortium staff, librarian, and non-librarian participants. 


\section{LITERATURE REVIEW}

There is no prior research on the topic of statewide OER initiatives and their governance structures. Little formal research exists at all on the subject of state OER initiatives and their operations, members, and impact. Most of what is known about these statewide efforts comes from local reports of their activity. It was reported that the Idaho State Board of Education joined the OTN in 2018 to create more opportunities among state colleges and universities to promote textbook affordability across the Idaho higher education system (Tomtas 2019). In 2016, Rhode Island instituted a statewide Open Textbook Initiative that brought together seven higher education institutions to use openly licensed textbooks. It now includes all Rhode Island higher education institutions (Raymond 2018).

In one of the few published pieces about statewide OER initiatives, Bell and Salem (2017) wrote about the advantages that statewide OER collaborations offered over individual institutional efforts. Having started textbook affordability projects at their respective institutions, the authors concluded that there were significant benefits to engaging many institutions to work together to advance OER awareness, adoption, and advocacy.

\section{Methodology}

Data were collected in two stages using a standard Google survey form. In the first stage, conducted in the summer of 2018, only statewide or consortium members of the OTN were contacted with invitations to participate. Within this stage, there were two unique surveys conducted. One of them was designed for the administrators or directors of the consortium or state government leading that state's textbook affordability initiative. The second version was directed to members or participants, primarily librarians, serving on a formal or informal committee, task force, or other group organized to conduct the work of the initiative. The author received the cooperation of the initiative coordinators to send an invitation to participate to all other organization participants.

In spring 2019, a list of state OER leaders was informally compiled to identify advocates within states leading textbook affordability initiatives. Individuals were invited to add themselves or colleagues they identified as OER leaders in their own state. This information was compiled in a Google spreadsheet located at http://bit.ly/oerleaders. While this list could omit the names of formal leaders working in some official capacity within a state network while including the names of individuals whose actual involvement in statewide OER initiatives is at best tenuous, it still provided information that proved useful to this research project by identifying additional individuals who could share their experience serving as a governance participant in a statewide project. Each individual whose name appeared on this spreadsheet was sent an email invitation to complete the participant survey. 


\section{FINDINGS}

With little known about the organizational and governing structures of these OER statewide initiatives, the collected data were used to explore several questions:

- What are the organizational structures of these initiatives, and is there any single model that is prevalent?

- Is there a single organizational model that is particularly effective for achieving the goals of these initiatives (e.g., education, training, awareness, increasing adoptions, etc.)?

- What is the experience of librarians serving on these governing bodies?

This research is intended to develop strategies for existing, developing, and future statewide OER initiatives. When the author's own state initiative was in the early stage of organizing, they found that information gathered from the few existing state OER groups yielded limited information about governance practices. The four states contacted had organized in completely different ways. One used mostly consortium staff to operate the initiative, with few practitioners contributing to the governance. Another organized a steering committee mostly composed of practitioners to serve as decision makers while consortium staff managed day-to-day tasks. Yet another organized several working groups for functional areas such as education, training, and advocacy. No single, dominant model emerged. While all of the initiatives could point to accomplishments and progress, the author and colleagues wondered which of these approaches could prove most efficient and inclusive for achieving their own goals. The following three sections share survey results from each of the three groups surveyed.

\section{OTN Members-Directors}

This group was the smallest population contacted as it included only the directors of the statewide organizational members of OTN. There are more organizational members, but some, such as the Boston Library Consortium, are not statewide. A total of ten responses were received. Respondents self-identified as either executive directors of a library consortium or directors of the consortium's affordable learning project. In 2018, all of the initiatives were still fairly new, with 80 percent in existence between six months and two years (see figure 1). Only one initiative had reached the three-year mark. The impetus to start the initiative was evenly divided between a request from consortium members and consortium staff (see figure 2). There was considerable variation in how respondents (eight of ten responded) described the governing structure of their initiative:

- Governed by a consortium staff member along with one librarian elected to serve as the system representative by the consortium board of directors

- Governed by an administrative team that reports to the consortium Scholarly Communications Advisory Group 


\section{How long has your consortia coordinated the OER initiative?} $\mathrm{N}=10$

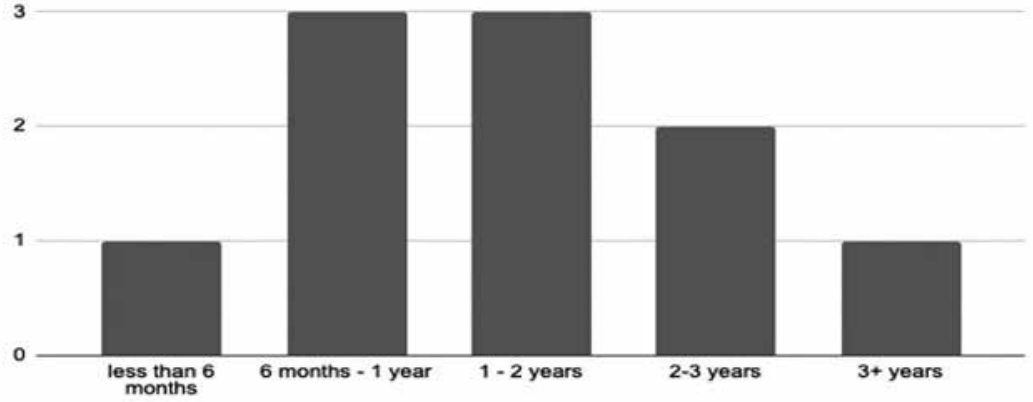

Figure 1. Age of consortium initiative.

Did the Motivation to Create Your Initiative Come From the Members or Consortia Staff? $\mathrm{N}=10$

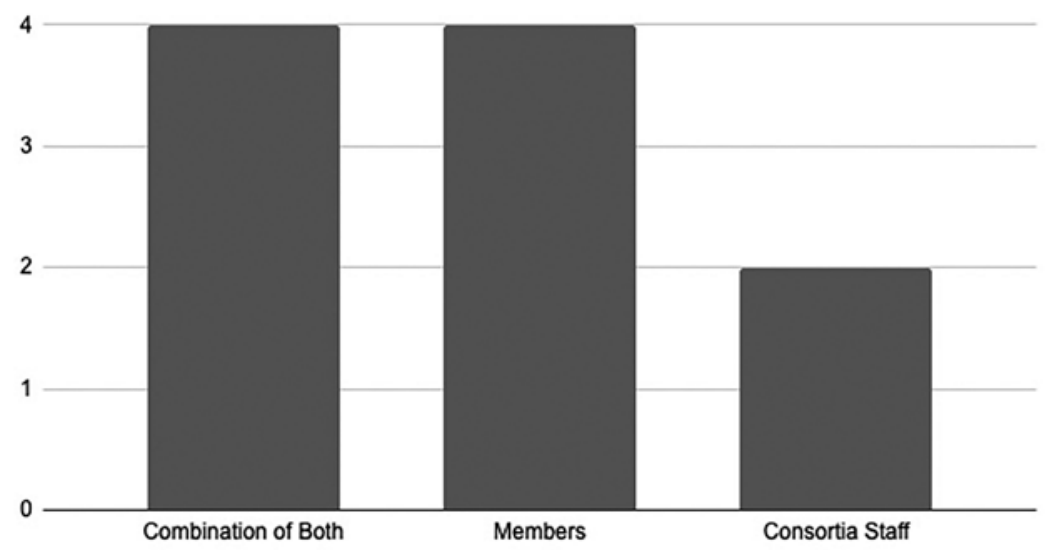

Figure 2. Motivation to create the initiative.

- Governed by an OER task force that reports to the consortium board

- Governed by a steering committee that includes two consortium staff members and eight library members that form an "affordable learning ambassadors" group

- Governed by an advisory committee that reports to the consortium's Librarians' Council (which reports to the consortium executive committee)

- Governed by an affordable learning administrators group, made up of one representative from each campus, that reports to the consortium executive director 
- Governed by a steering committee that includes consortium staff and representatives from member institutions, a representative from the state library, and a representative from a community college; tasks delegated to a team of OER specialists and "campus partners" (one "partner" from each member institution)

- Governed by the state Board of Regents that provides funding and direction, with day-to-day oversight by the consortium executive and staff, with support from a group consisting of one librarian representative from each member institution

The number of librarians who serve on the designated governing body averaged six to ten members at 50 percent of the responding consortia, one to five members at 20 percent of the responding consortia, and more than ten librarians at 30 percent of the responding consortia (figure 3 ). The consortium leaders were asked to share information about the academic professionals who participate in their governing bodies. As anticipated, the majority, at 80 percent, are academic librarians. Other participants rounding out the governing bodies are non-librarian faculty, instructional designers, and other teaching/learning center staff. These participants put most of their effort into organizing programs for other members of the OER initiative, facilitating awareness about and the adoption of OER and collecting data about or assessing these activities. Among the most routine functions or activities of those governing body members are (number reporting this activity by percentage):

- Coordinate OER initiative programming (80 percent)

- Conduct OER training courses (70 percent)

- Conduct data collection or assessment activity (60 percent)

- Serve as their campus liaison for local programming (40 percent)

- Establish policies to govern the initiative activity (40 percent)

- Review proposals/applications for funding (30 percent)

One governance area where there is considerable variability is in how members are selected for the initiative governing body. Among the ways it happens are:

- Selection by a central steering committee

- Selection by the consortium staff through an application process open to all member institutions

- Selection directly by the consortium board of directors

- Selection by a state organization that funds the consortium

- Informal channels in which participants express their interest in serving

- Appointment by the library dean

- Some combination of all the other selection or appointment methods 


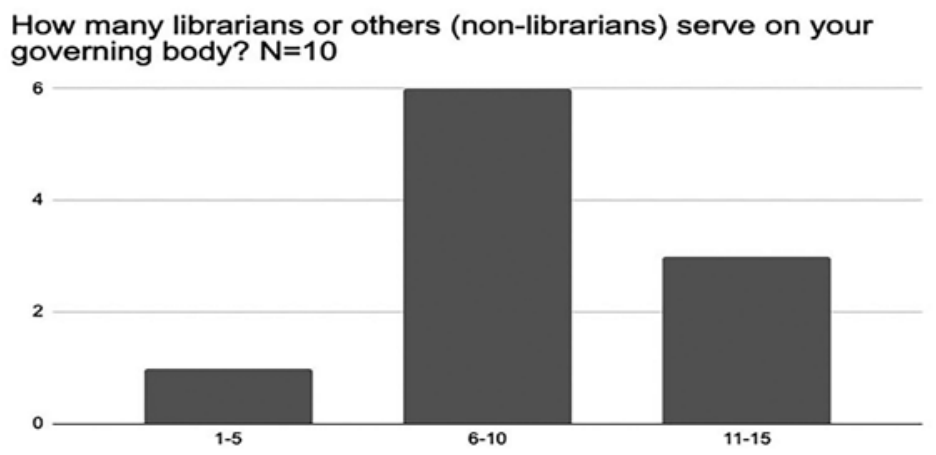

Figure 3. Number of librarians serving on the governing board.

What else did the directors survey reveal about these consortia OER initiatives? At the time of the survey, only half of them had a formal governance document for their initiative. The majority of those who did made it publicly available on their consortium website. The majority, at 60 percent, had attended at least one OTN Summer Institute, where attendees from consortia and independent institutions received OER advocacy training. Organizing the initiative happened quickly for the majority of respondents. There was little advance planning, and it usually began in response to a recognized internal need or member pressure to join the effort to advance OER awareness and adoption. As a result, structuring the governance was more haphazard or improvised than well planned out in advance. There was a clear sense of urgency to seek funding or engage member institutions in order to leverage the advantages of a statewide effort.

\section{OTN Members-Governance Participants}

Among the ten OTN consortium members contacted, it was unclear how many were librarians or other professionals. The invitation to participate came from the consortium administration, not the author. A total of twenty-six individuals responded to a survey constructed specifically for librarian and non-librarian governance participants. The majority of those responding self-identified as scholarly communications librarians. Other reported positions include variations on reference or public services librarian, distance services librarian, and collections librarian. Only three positions were specific to OER, such as open education librarian. The author's observation, based on the appearance of position advertisements for OER librarians, is that there were far fewer of these positions at the time of the survey than there are now. Two respondents identified as consortium staff, most likely coordinators assigned to lead the OER initiative project. The majority of the respondents reported their home institution as a doctoral research institution. That was followed directly by four-year liberal arts colleges and then community colleges (figure 4). The LOUIS (Louisiana) 


\section{Which of the Following Describes Your Library? $\mathrm{N}=\mathbf{2 6}$}

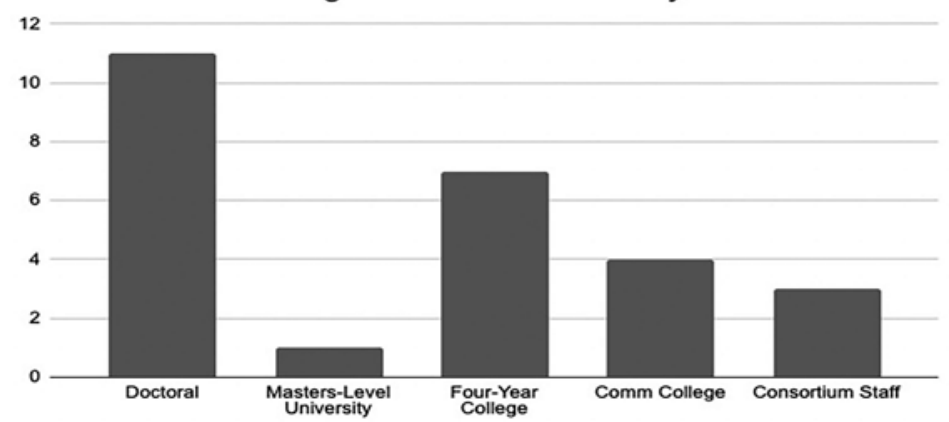

Figure 4. OTN participants' type of library.

consortium was the most represented, with 39 percent of the respondents. Other consortia represented in the participants' survey were PALNI (Indiana; 23 percent), CARLI (Illinois; 15 percent), and OhioLINK (Ohio; 12 percent), with MOBIUS (Missouri), FALSC (Florida), VIVA (Virginia), and NCLIVE (North Carolina) represented with less than 5 percent of the respondents (figure 5).

If a college or university library currently supports its own local textbook affordability initiative, do staff from those institutions tend to dominate the participation in statewide initiatives? To an extent, that may be the case, as 50 percent of the respondents replied that their institution did currently support its own OER or textbook affordability initiative. Another 27 percent of the respondents indicated they were currently in the process of planning their local initiative. The remaining 23 percent indicated they had no faculty or administrative support, had a previously failed initiative, or have never attempted to develop one (figure 6).

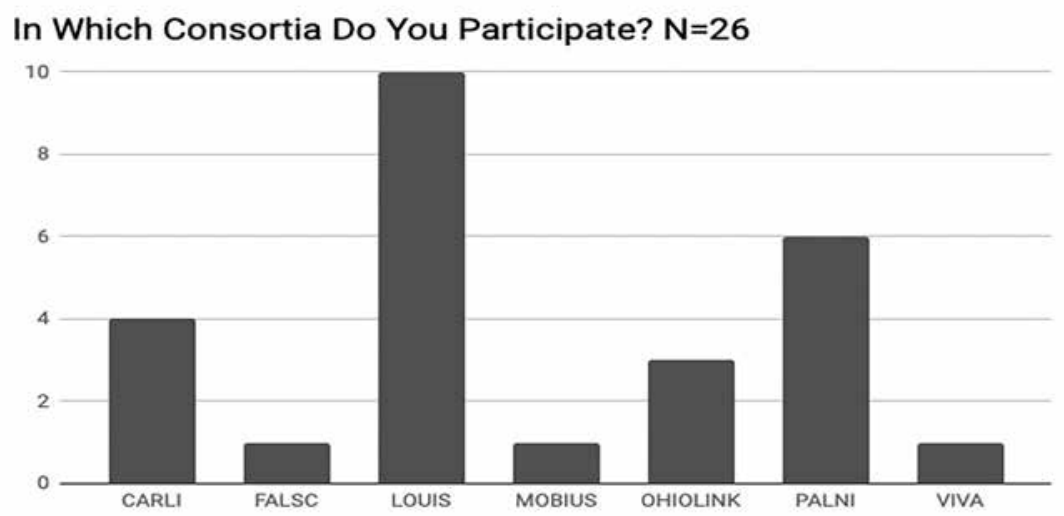

Figure 5. OTN participants' consortium affiliation. 


\section{Does Your Library/Institution Currently Support an \\ OER/Textbook Affordability Initiative? $\mathrm{N}=\mathbf{2 6}$}

15

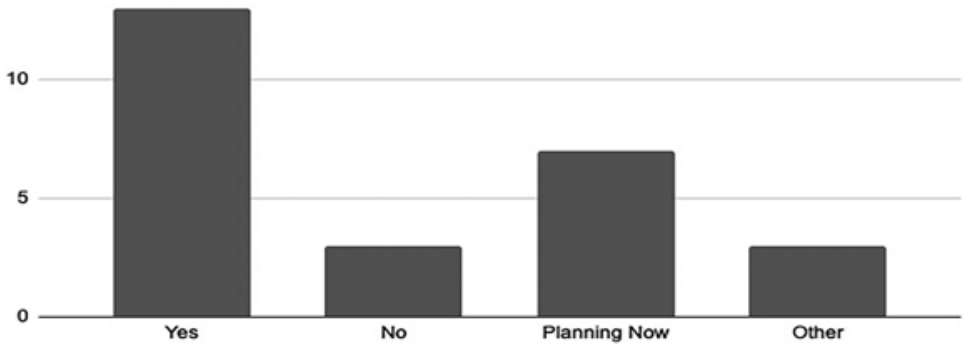

Figure 6. OTN participants' OER/textbook affordability initiative status.

As most of the statewide OER initiatives were fairly new at the time of the survey, a lack of experience was reflected in those who participate in the governance structure. The majority of them, at 40 percent, had served for less than two years. Another 32 percent served less than one year. Just a few, or 28 percent, had served three years (figure 7). When asked to describe their own OER experience prior to joining the governing body of their statewide initiative, respondents revealed a relative lack of experience with OER issues or fundamentals. The majority of respondents, at 80 percent, described themselves as either "beginner/novice" or "basic knowledge but relatively new," while the remaining 20 percent claimed "advanced/expert" knowledge or "experienced but not expert" at the time they joined the initiative (figure 8). Serving on the governing body of a statewide OER initiative has a strong positive impact on adding to or improving the OER knowledge or skill level of participants. An overwhelming 89 percent of respondents indicated that serving had increased their OER knowledge and skills (figure 9). That benefit of serving on the governing body quite likely led 58 percent of the respondents to describe their experience as "excellent," while another 31 percent described it as "good" and the remaining few as "fair" (figure 10).

While consortium staff are typically assigned to work with the governing body, there are a variety of ways for participants to become members of the governance structure. Among the commonly stated paths, the most frequently mentioned was "responded to a call for participants" followed closely by "appointed by dean":

- Responded to a call for participation from my statewide consortia (seven respondents)

- Appointed by my library dean or immediate supervisor (six respondents)

- Already participating in consortium scholarly communications committee (six respondents) 


\section{How Long Have You Served on the Governing/Coordinating Body? $\mathrm{N}=26$}

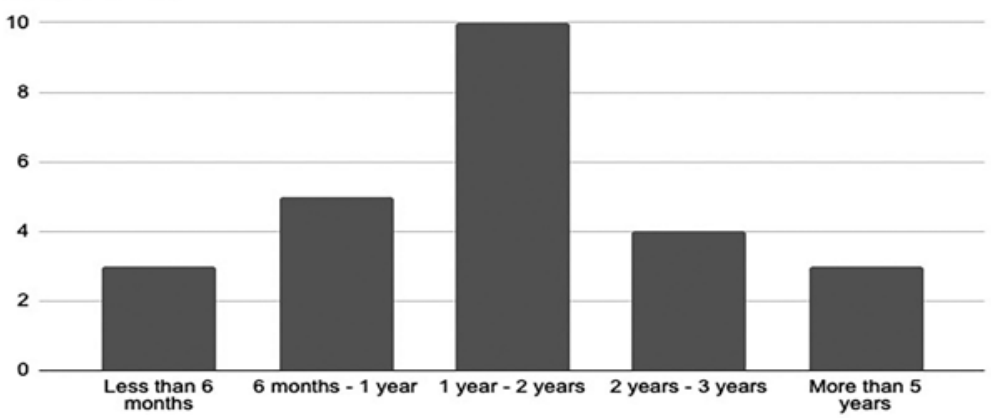

Figure 7. OTN participants' length of time serving on governing body.

\section{What Was Your OER Experience Level Prior to Joining the Governing/Coordinating Body? N=26}

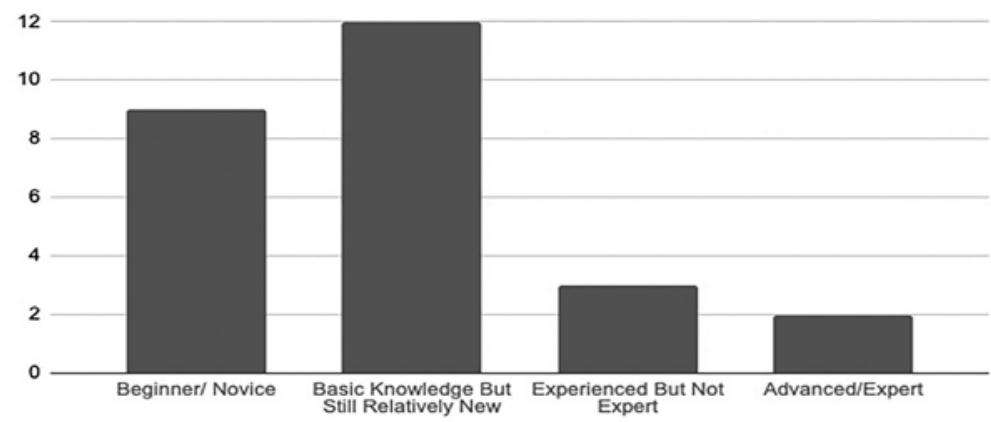

Figure 8. OTN participants' prior OER experience.

\section{Has Participating on the Governing Body Changed Your OER Knowledge/Skill Level? $\mathrm{N}=26$ [Note: No decreases reported]}

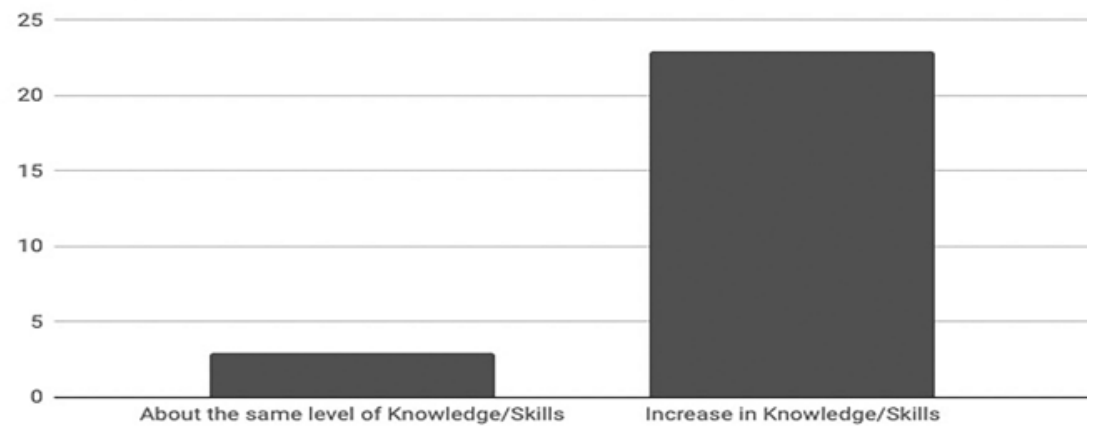

Figure 9. Impact of participation on OTN participants' OER skills. 


\section{How Would You Describe Your Experience on the Governing/Coordinating Body? $\mathrm{N}=26$}

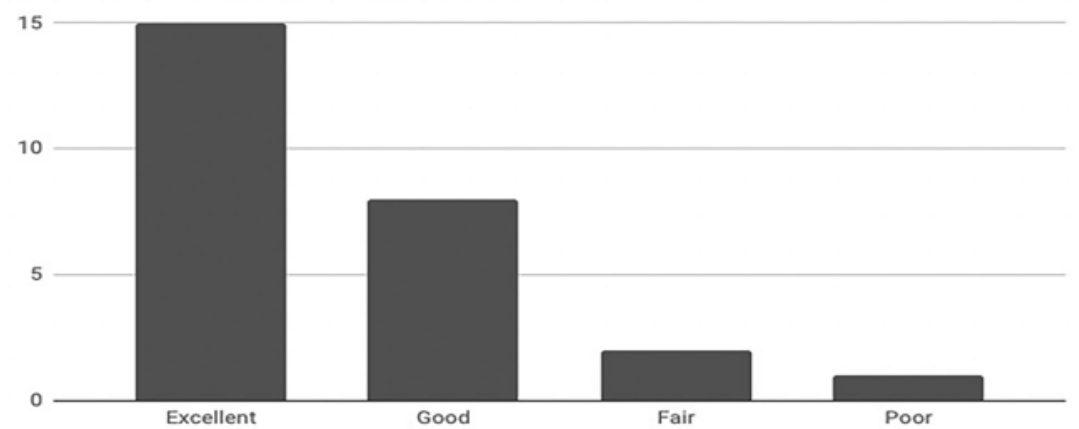

Figure 10. OTN participants' governing body experience.

- Joined owing to individual interest in attending the OTN Summer Institute (two respondents)

- Invited to join owing to connection to my position responsibilities (two respondents)

Respondents further elaborated on their path to participation by sharing their personal motivation for joining the governing body. These reasons can be grouped into the themes below. The most frequently cited reasons for joining the governing body were serving at the request of dean or other administrator, desire to further engage with OER, and advancing OER adoption:

- Serving at the request of library dean or another administrator (five respondents)

- Desire to further engage with OER resources or gain experience with them (five respondents)

- Advance OER adoption and awareness with consortium colleagues (four respondents)

- Fulfill the library's mission to promote open access and open solutions (three respondents)

- Support economically disadvantaged students by eliminating or reducing textbook costs (three respondents)

- Become the OER leader at my institution (two respondents)

- Past satisfactory experience in consortium projects and desire to work on new project (two respondents)

With multiple structural variants on how statewide OER initiatives organize and engage participants in conducting the work of the initiative, the survey sought to learn more about the ways in which governance participants serve. Participants described a variety of committee assignments that 
facilitated their ability to contribute to OER activity. The coordination of these committees typically fell to consortium staff, or they reported to a consortium leadership group. Based on comments about their responsibilities, these participants are multitaskers. While most of their work revolves around developing workshops and promotional material and promoting the OER initiative, they are also involved in policy development, advocacy, and coordinating between the statewide initiative and their campus. The more general tasks and responsibilities identified by the respondents include:

- Promote the OER initiative, policies, and events to institutional stakeholders

- Develop educational and promotional materials to create textbook affordability awareness

- Develop and coordinate educational workshops for librarians and faculty

- Organize a statewide OER annual summit

- Support member efforts to develop OER resources

- Participate in seeking funding and grants to support initiative activities

- Contribute to data collection and tracking of OER adoption

- Communicate initiative activity back to my institution

More specific tasks, such as developing or maintaining a LibGuide or other website related to OER, are shared in the responses, but most of the tasks focus on the education, training, and promotion goals of statewide initiatives. Support for publication and dissemination of OER texts and learning objects was mentioned but appeared infrequently as a specified task. These tasks are likely to increase as more project participants develop OER publishing capacity, along with the ability to establish statewide repositories to retain and provide access to this open content.

It is also of interest to go beyond why respondents commit to participation in statewide OER initiatives to learn what they get out of that experience. Respondents were asked what they thought was the best thing about their governing body participation. Several themes emerged:

- Working together with like-minded colleagues for a good cause

- Creating awareness about OER on and beyond their own campus

- Contributing to a valuable cause that is bigger than their own work

- Knowing the statewide initiative benefits from colleagues working together and accomplishes more than single-campus programs

- Getting to work with instructional designers, faculty, consortia staff, and other non-librarian colleagues

- Opportunities to learn more about OER and how to become an effective advocate

- Building an OER community for our state that also contributes to national-level projects 
These are the types of responses the author would expect from librarians who support textbook affordability activity. Respondents' open-ended comments expressed clear passion for their work as they seek opportunities to achieve more beyond their own campus:

I'm learning a great deal and getting to know people at other institutions who have a great deal more experience than I do.

Community! We do more together.

The overall excitement and motivation from the members. It's fantastic to work with people who want to collaborate on such a big task as a consortium OER initiative.

Everyone is very passionate and proactive about promoting OER and helping students and faculty.

There was a noticeable absence of comments related to direct support of students and their need for a more affordable education. Perhaps it was hardly mentioned because it is so obvious. The responses make little reference to the creation or publication of new OER. While that was hardly an unknown practice at the time of the survey, far fewer OER initiative participants had achieved experience in this area, and statewide initiatives were focused on more fundamental issues such as education, awareness, and funding.

These statewide projects present their share of hurdles and barriers to effective participation. Many are formed as grassroots efforts and develop, at first, with limited formal planning and organization. There is a desire to take action and get results and to do so on a fast track. To gain more insight into the challenges or frustrations that the participants encountered in their governance experience, the survey asked them to identify the most challenging or disappointing thing about serving on the statewide initiative's governance group. Several themes emerged from their responses:

- Lack of support and recognition for these initiatives outside of the academic library

- Too little awareness of the work accomplishments of the statewide initiative

- Conflict in reaching consensus on how to best achieve the work of the initiative

- Insufficient time allowed by supervisors to devote to the work of the initiative

- Frustration with the lack of knowledge library administrators have about OER

- Need for more support of the initiative than just the designated librarian

Some responses alluded to an internal conflict between keeping the work focused on "affordability" as opposed to OER adoption and publication. 
In the landscape of OER initiatives, both institutional and statewide, "textbook affordability" is sometimes used interchangeably with or in addition to OER. Whereas OER refers specifically to openly licensed materials, textbook affordability includes non-OER affordability solutions such as licensed library or free web-based content. Some advocates believe that resolving the textbook cost crisis is primarily or only a conversation about advancing OER. Others bring a broader perspective to this conversation by including other no-cost learning material options:

I would like this group to do more. However, there is political pressure to cave to "affordability" rather than investing in open. I find this very discouraging. There is little will to invest in creating OER that we really need.

The leaders of the consortium know less about OER than the system leaders and sometimes make decisions that have negative impact on open by adding library subscriptions to the mix.

The difference between "affordable" and "open" is a familiar source of tension in the OER community, as reflected in these comments, where more vocal advocates for openness want to focus on open, no-cost solutions and are less willing to accept low-cost, non-OER options as acceptable. Comments from respondents sounded a familiar refrain about the value and power of academic libraries and consortia working together to achieve great things. Despite identified concerns, governance participants overwhelmingly expressed a desire to do even more to support OER adoption and publication throughout the state.

\section{OER State Leaders}

An additional thirty-seven survey respondents were reached after their names appeared on an informally organized spreadsheet of state OER leaders. An invitation to add the names of formal or informal state OER leaders led individuals to add either their own name or the names of other recognized leaders in their state. The author emailed all 138 of these individuals to invite them to reply to the same survey as the governance participants serving on OTN member organizations. To avoid duplication, the email invitation indicated that those who previously responded should ignore the message. The resulting added responses reflected a broader group of participants from organizations beyond OTN and included new types of respondents. As the responses from this informal group bear resemblance to the OTN responses shared above, this section primarily focuses on the characteristics of these additional respondents and any unique responses to the survey questions that shed new light on the roles, responsibilities, and perspectives of statewide OER initiative governance participants.

The job titles listed by respondents to identify their institutional roles reinforce that most of the statewide initiative participants are academic 
librarians and that their primary roles are in the scholarly communication, public service, and electronic resource coordination areas. A lesser number of respondents described their role as library deans, directors, or other academic administrators. The modes by which the respondents engaged in a state leadership role were also similar to the OTN respondents. It was most frequently a nomination or appointment by a dean or director, by virtue of staff position (e.g., OER librarian), by invitation to join the steering committee, or through involvement in a state-level library committee or organization. Compared to the OTN respondents, this group's responses suggest their participation was based on some preexisting expertise with textbook affordability and OER projects.

While the majority of the respondents in this group were from research universities and four-year colleges, the number of participants from these institutions was less dominant owing to greater institutional diversity in the state OER leaders' group. More state government agency and consortia staff were represented, but the representation from higher education institutions was more evenly divided in this group, although community colleges continue to be less well represented (figure 11). By comparison, a significantly higher number of these community college respondents (73 percent vs. 50 percent) reported that their institutions supported an OER initiative (figure 12). While this leaders' group participated in the survey approximately seven months after the OTN participant group, that is unlikely to account for the difference. Rather, it is more likely that these leaders gained their stature by virtue of personal practical experience with an institutional OER initiative. In terms of the amount of time spent working for the state-level initiative, the two groups were roughly the same. If anything, the OTN respondents had slightly more time spent in their governance roles. While 12 percent of the OTN group had more than three years of participation time, no one in the state leaders group indicated more than three years of experience. Yet 51 percent of the state leaders group had between six months and two years of experience, while 60 percent of the OTN group had the same limited amount of governance time (figure 13).

Despite reflecting a more diverse and representative body of participants than the OTN group, there was still relative similarity in the reasons that motivated the respondents to take on a statewide initiative governance role. Common responses included wanting to make higher education more affordable and accessible for students, a desire to promote the adoption of OER by educators, the opportunity to learn more about OER, wanting to expand OER initiatives to new institutions, seeking more involvement for the institution, and other responses that reflected the leaders' passion for seeking change and social justice through OER and textbook affordability initiatives. To be sure, some of the responses were more mundane, reflecting that participation in the state initiative was a job responsibility or owing to a directive from above. 


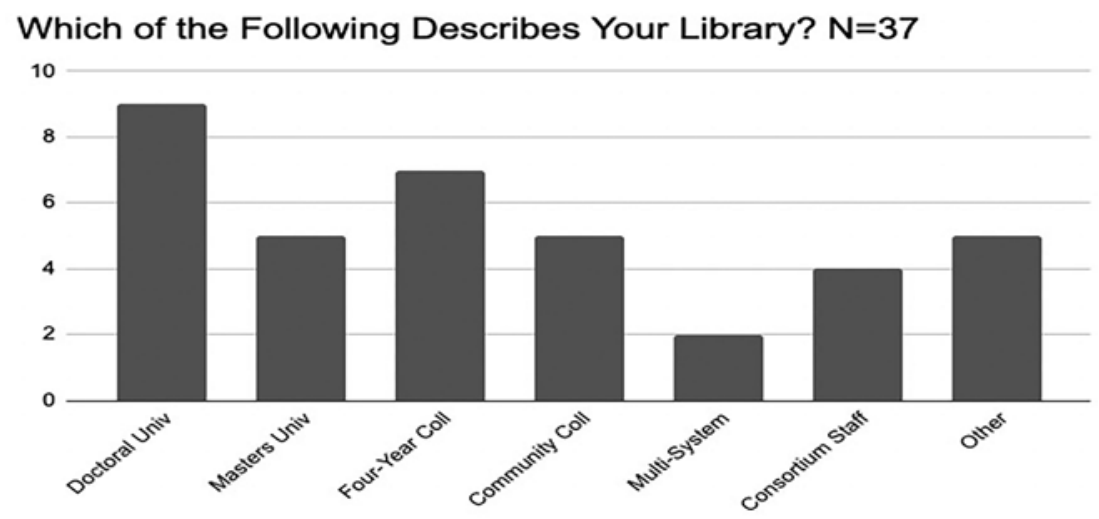

Figure 11. State leaders' type of library.

\section{Does Your Library/Institution Currently Support an OER/Textbook Affordability Initiative? $N=37$}

30

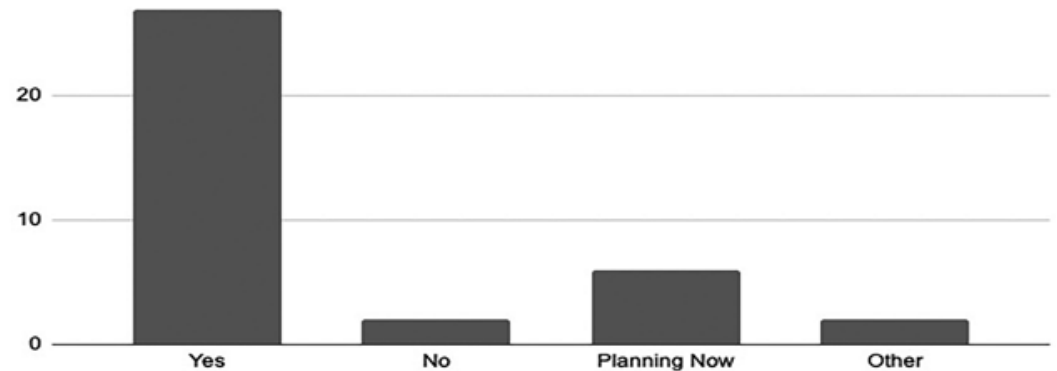

Figure 12. State leaders' OER / textbook affordability initiative status.

\section{What Was Your OER Experience Level Prior to Joining the} Governing/Coordinating Body ? $\mathrm{N}=37$

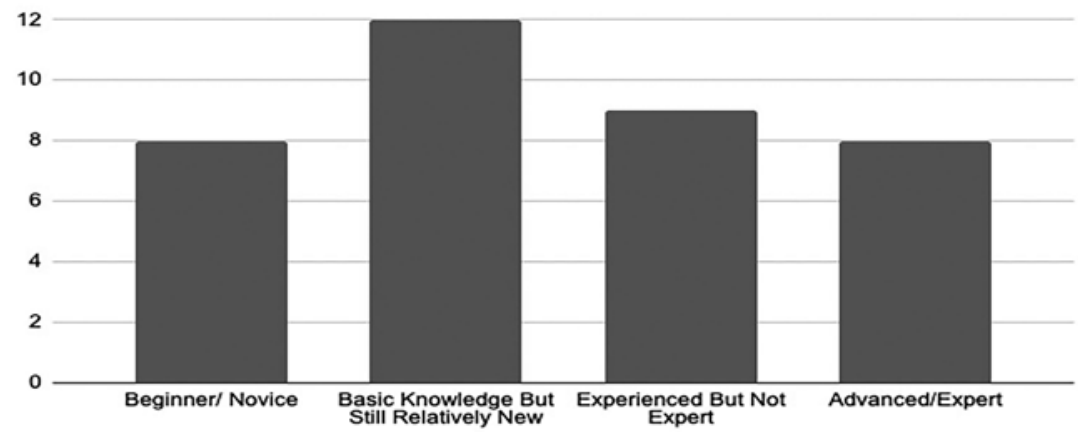

Figure 13. State leaders' length of time serving on governing body. 
One area where the two groups of respondents, OTN and state leaders, differ more considerably is in their personal experience with OER upon joining the statewide initiative. The state leaders group showed a greater number of respondents reporting advanced or significant experience, at 46 percent, compared to just 18 percent in the OTN respondents. The OTN group reported 76 percent having only novice or basic experience with OER, compared to just 54 percent for the statewide leaders (figure 14). Yet despite this difference in reported experience with OER, the two groups were nearly identical in the high percentage reporting that participation in the statewide initiative governance increased their knowledge of OER (figure 15). Where the two groups once again achieved high similarity was their acknowledgment of having an excellent or good experience participating in their statewide initiative, with an average of 90 percent satisfaction among them (figure 16).

\section{What Was Your OER Experience Level Prior to Joining the Governing/Coordinating Body? $\mathrm{N}=37$}

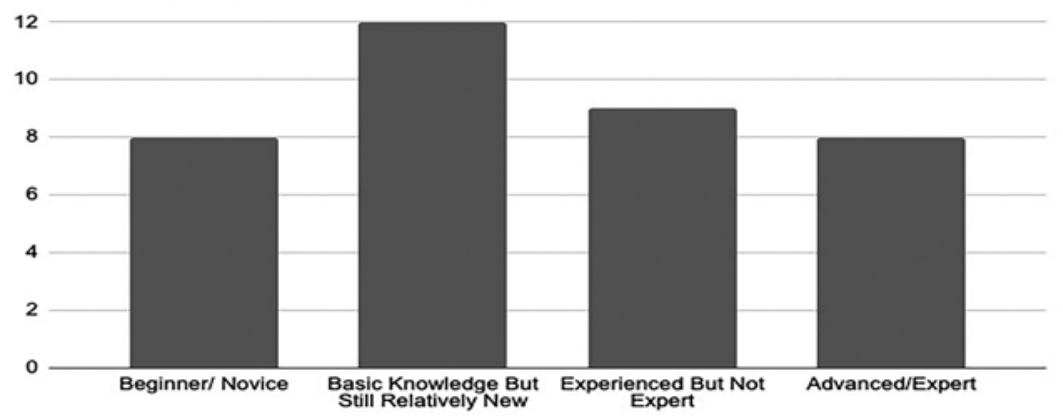

Figure 14. State leaders' prior OER experience.

\section{Has Participating on the Governing Body Changed Your OER Knowledge/Skill Level? $\mathrm{N}=37$ [Note: No decreases reported]}

40

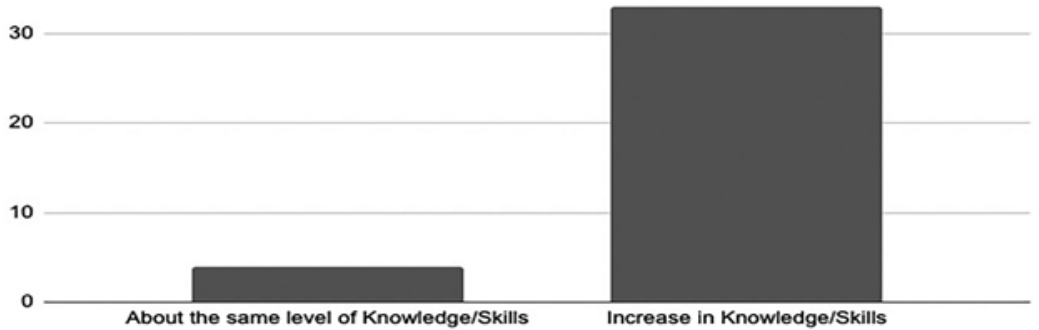

Figure 15. Impact of participation on state leaders' OER skills. 


\section{How Would You Describe Your Experience on the Governing/Coordinating Body? $\mathrm{N}=37$}

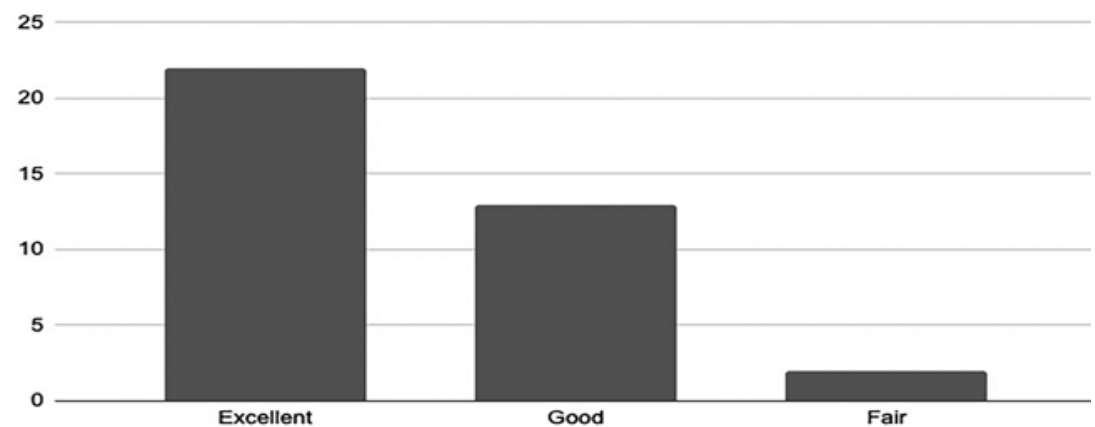

Figure 16. State leaders' governing body experience.

The statewide OER leaders reported an extensive number of tasks or responsibilities they performed in their roles as initiative leaders. Many hold common ground with the work of the OTN governance participants, and they center around six activities: (1) offer face-to-face and online education and training; (2) create advocacy, outreach, and awareness campaigns; (3) develop and hold programs and events; (4) formulate and advance OER policies; (5) identify and secure grants and funding; (6) facilitate data collection and analysis. Depending on the state, any of these tasks can take on local qualities, such as working with a state education agency, organizing annual conferences, developing policy with government offices, serving on internal governance committees, or representing the consortium in national organizations. Based on the responses from both groups to this question, an obvious advantage of participating in statewide OER initiative governance is the opportunity it provides to librarians and other professionals who want a more intense and varied open textbook experience that exceeds what can be accomplished at a local institution.

When asked to share examples of the type of projects they worked on or contributed to, the responses from the state leaders demonstrated the varied types of experiences available to statewide initiatives to participants. Many of the projects were educational in nature, such as organizing and presenting webcasts, conducting workshops on behalf of the initiative, and creating learning resources. Other tasks were mostly related to program activity or work on grants. Compared to the OTN cohort of participants, there appeared to be fewer mentions of policy or advocacy work. It may be that the respondents, when thinking about tasks performed, focused more on their institutional work than what they did on behalf of the initiative.

Given that more participants responded, and many more states were represented in the responses, what the state leader respondents enjoyed about their participation as well as what challenged them produced an 
extensive list of positives and negatives. Far and away, the opportunity to contribute to the advancement of OER and textbook affordability on the state level to the benefit of students was the most mentioned reward.

The best part is simply being involved in an important initiative with a mandate that is in the best interests of our students.

Knowing you are launching a program that may make college more accessible and affordable.

Hearing the stories from students on how much they saved and getting feedback from faculty that student outcomes seem to be improving.

There were many mentions of the value of libraries working together for a common goal. Personal satisfaction and learning were also high on the list of benefits. Others pointed to their work having a positive outcome on the advancement of OER and textbook affordability on their campus.

Being a state leader in OER allow[s] me to share what I've learned about OER, Creative Commons licensing, how both benefit students and faculty, and how it works at this institution.

As is often the case in collaborative library projects, networking with colleagues and making new professional associates were frequent comments.

Most of the challenges focused on funding and the inability to obtain it at desired levels to allow all state academic institutions to participate. There was also a similar issue to the one reported by the OTN respondent group, related to friction between those wanting to advocate primarily or strictly for OER versus focusing on all types of textbook affordability options.

Some library directors in the state see OER only as a textbooks and costsaving measure and have gotten the consortium to apply incentives to use library resources ... and not paying any attention to emphasizing the affordances of OER.

Also mentioned multiple times was the lack of time and energy to devote to the statewide initiative. Others expressed frustration dealing with government agencies and slow progress owing to bureaucratic barriers.

Finding time to work on these projects. OER is an added responsibility I have taken on in addition to my other responsibilities.

Things move too slowly and we lose momentum.

Finally, participants expressed frustration over the slow pace or lack of change at their own institutions, despite their contributions to the state initiative.

Despite barriers and frustrations that confront participants in statewide OER initiatives, it is clear from their survey responses that they experience a wide range of benefits as a result of their participation. While doing so adds to their workload, there are intrinsic and intangible benefits, such as 
seeing students have a more affordable education. There are also concrete benefits, such as developing greater expertise in their knowledge of OER, Creative Commons licensing, the textbook publishing industry, and other skills not traditionally associated with academic librarianship. Statewide initiatives appear to have little difficulty attracting librarians and others to serve on them, but do the current governing structures in place allow these participants to make the most of their participation? Are the governance models and organizational structures in place effective to accomplish the goals of advancing OER and enabling college students to have greater access to an affordable higher education? While this research provides insight into the types of models and those who work within them, it does not lead to a conclusion that any one governance model is most optimal. Some recommendations do emerge from the findings that can enable statewide OER initiatives to design the governance model that best leverages their available resources while meeting the needs of stakeholders.

\section{Recommendations for Statewide OER Initiatives}

As librarians across the country form statewide OER initiatives, they will work with consortia and state government personnel to create governance structures to guide their work. Like the author's own state initiative did as it first organized, it helps to examine governance structures already in place to identify examples of what works well. New and evolving initiatives could choose to adopt an existing model, build a variant based on a best of breed approach, or create a completely different model not previously tried. The "OTN Members-Directors" section above identified eight different governance models, demonstrating considerable variation, and those came from only a small population of the earliest statewide initiatives. Based on that and other survey responses, there are six recommendations for existing, developing, and future statewide OER initiatives. One assumption, and therefore not a recommendation, is that all statewide initiatives will form a central steering committee to guide the overall coordination and direction of the initiative, including policy setting, strategic visioning, collaborations with other consortium and external agencies, critical decision making, and engagement with other high-level matters of importance.

\section{Recommendation 1: Involve Library Practitioners in Governance}

One of the most common features of the governance models is the combination of academic library consortium staff and academic library practitioners coming together to form the organizing structure. What shape that takes is largely dependent on the nature of the consortium. The larger consortia, owing to having greater staff and funding resources, can afford to take on the bulk of the work that governance bodies perform. Those with fewer resources will need more librarian participation. In either case, the first recommendation is to involve library practitioners as much as possible in the governance structure. One way to achieve this goal is to add 
working groups beyond the core steering committee. Starting a statewide initiative will put many more institutions in a position to advocate for affordable learning materials. Actually getting the work done requires the coordination of many librarians performing small but essential tasks. It is the role of the steering committee to identify the tasks and priorities and then put the teams into place that can advance the goals of the initiative.

\section{Recommendation 2: Strive for Diverse Representation}

There is an additional advantage to creating a structure with multiple working groups or teams. The second recommendation is to create a governance structure that optimizes the opportunity for broad, diverse representation from across the state. While it may be possible to create that sort of institutional type and geographic location diversity within a steering committee, its limited size presents a barrier to a more desirable level of participation. One way to achieve this goal is to create an organizational group composed of one leader from each participating institution to serve as a campus representative. These individuals serve as connectors between their campus and the OER initiative, as well as serving as potential participants for a variety of working groups.

\section{Recommendation 3: Prioritize Enthusiasm and Commitment over Experience}

One particularly important revelation appeared in the survey responses. In both the OTN and state leaders' groups, a high percentage of participants indicated a significant level of limited experience with OER. An even higher percentage, an average of 88 percent, responded that their participation in a statewide OER initiative increased their skills and knowledge of OER and textbook affordability. The third recommendation for statewide initiatives is to look for enthusiasm and commitment, not just experience, in identifying governance participants. Owing to their apparent ability to develop the necessary experience in a short period of time, it is hardly necessary to choose participants based solely on experience. This also speaks to the quality of support and education that statewide initiatives can provide, such as sending participants to the OTN Summer Institute or hosting an in-state OTN workshop, to allow them to serve as a launching pad for a statewide team of OER and textbook affordability experts.

\section{Recommendation 4: Include Training for Your Advocates}

There is another reason to create a governance structure that maximizes the opportunities for broad participation. While allowing more librarians and others to participate is one way to ensure that there are adequate numbers of people to do the important work of the initiative, the fourth recommendation is directly connected to a core reason for statewide OER initiatives to exist. Initiative goals should include training and developing a body of OER advocates who are empowered to spread the ideas of openness and engagement with textbook affordability at their institutions. 
Comments from the survey reinforced that participation in the statewide initiative, plus exposure to training and education, gave participants at all levels of experience more confidence in their ability to serve as advocates for OER and textbook affordability. For example, governance participants typically become skilled at refuting OER myths or responding to faculty questions about OER quality or availability. When states lack an initiative and only a few well-resourced institutions have access to OTN training or the ability to send one staff member to OER conferences or hire an OER librarian, far fewer institutions benefit from a local campus OER advocate, which ultimately slows the growth of statewide textbook affordability progress and limits funding opportunities.

\section{Recommendation 5: Provide Opportunities for Engagement}

Other recommendations stressed the importance of inviting librarians from all consortium members to participate in the governance structure. Doing so succeeds only if the governance structure is configured to provide opportunities for participants to actually accomplish purposeful tasks. Inviting participation and offering training will surely be a frustrating experience if the governance structure then offers little or no opportunity to engage with a challenge. The survey comments clearly demonstrated that the greatest source of value for participants is making a contribution to the advancement of OER adoption and awareness. The fifth recommendation is to create any of several types of working groups that well-structured statewide initiatives should consider as engagement opportunities:

- Education and training-Develop and organize training programs across the state; offer regular webcasts aimed at professional development; organize and manage the annual statewide OER summit; develop an OER training materials repository

- Communication and promotion-Market and promote the initiative's education and training programs; provide faculty OER champions to speak to faculty at other institutions; prepare op-ed pieces for local media outlets; conduct social media campaigns; develop and maintain the initiative's website

- Assessment and data-Conduct surveys and obtain feedback on behalf of the initiative; develop an institutional directory of OER projects; build a statewide data collection bank; prepare data for annual reporting; recommend standards for data collection

- Publishing support-Research a preferred platform for open textbook publishing; provide technical support for preparing open textbooks; train librarians in the fundamentals of OER publication; obtain assistance from national experts

- Funding outreach-Identify potential sources of support for initiative projects; prepare grant proposals; prepare reports to funders; research and develop new projects for funding 
- Rewards and recognition-Plan events and activities targeted at celebrating individual and group accomplishments; assist librarians with campus rewards and recognition activity; create a clearinghouse of reward and recognition programs

Creating, staffing, and leading teams require additional work. It is usually the responsibility of the steering committee to develop the charge and goals that govern their creation and ongoing development. It may require consortium or agency staff to provide logistical or resource support to these working groups. But the additional work is well worth it. In addition to giving representatives important responsibilities, just a few working groups can exponentially expand the statewide OER initiative's capacity to create change and make a difference.

\section{Recommendation 6: Identify an Initiative Project Coordinator}

Potentially the single most challenging barrier to accomplishing the work of the statewide initiative is the significant amount of time and energy required of participants. When asked about what frustrates or challenges them the most, multiple participants commented that lack of time and other job responsibilities keep them from engaging at a desired level. The sixth and final recommendation is to include an initiative project coordinator in any governance structure. This part- or full-time position usually reports to consortium or supporting agency staff. Whether it is coordinating the work of various committees, organizing the governance meetings, making arrangements for the annual symposium, or any one of dozens of managerial tasks, without a dedicated individual paying attention to all the details, large and small, it is far less likely that the initiative will accomplish all the things it needs and wants to do. While some consortia may have a staff member who is readily available to serve in this role, other statewide initiatives may need to obtain external funding support to enable the hiring of this critical position in the governance structure.

\section{ConcluUsion}

For all of its advances, primarily in the expansion of available open textbooks, the OER movement is still relatively new. It is primarily in the last decade that awareness of a textbook affordability crisis for college students has gained widespread national attention. Prior to 2010, the Student Public Interest Research Group criticized publisher practices that drove up the price of textbooks. But their 2010 publication, A Cover-to-Cover Solution, drew far more attention to the textbook crisis, particularly from the academic library community. Each year, more faculty respond in national surveys that they know what OER is and more indicate they are adopting it (Seaman and Seaman 2020). Yet OER advocates know there is still much to be accomplished. Many faculty still assign expensive commercial publisher textbooks. The textbook industry is hardly standing by while OER and 
used textbook sales further cut into profits. New digital publishing models being presented as affordable are opening new frontiers of questionable data collection and privacy practices (Vitez 2020). Now more than ever, higher education needs statewide OER initiatives to enable colleges and universities to plan and act together in ways to support affordable learning for their students. They will accomplish more by working together than would be possible individually.

The research presented in this article makes a case for why statewide effort is a critical path for the future of OER and other textbook affordability strategies. No single institution or its librarians can do all the advocacy, education, and awareness-raising work that is necessary to achieve progress, long-term sustainability, and a successful systematic conversion to mass OER adoption. No institution can single-handedly obtain the required funding to advance OER adoption at a large scale. As colleges and universities collaborate, their librarians leading the way with support from consortia and government agencies, they will go further in building a wellstructured and governed OER statewide initiative. Doing so depends to a large extent on putting that optimal structure into place. On the horizon, as statewide OER initiatives grow, we may see even larger collaborations emerge, possibly mega-state initiatives involving regional coalitions. Existing regional higher education compacts, such as the New England Board of Higher Education (NEBHE) and the Western Interstate Commission for Higher Education (WICHE), are already establishing OER publishing and adoption of OER as high-priority regional initiatives. There are opportunities for future research into the statewide OER initiative, how their operations and governance are evolving, and their relationship with and impact on learning material choices by educators. Librarians could explore the extent to which support and training from statewide initiatives contribute to the adoption of OER among their faculty. More in-depth interviews with statewide OER initiative leaders and participants could yield deeper insights beyond what this initial research reveals.

This research provides a window into the different organizational structural models with the intent of allowing existing, new, or planned statewide OER initiatives to create the governance structure that best meets the needs of its stakeholders. It is unlikely that one model would become the standard adopted by each initiative, but every statewide initiative, knowing what the different governance approaches are, can make the choice of model that works best for its members. When that happens, we may see just a few models rise as those considered most optimal for accomplishing the work of the initiative. As one respondent commented, "My institution does not currently have an OER initiative. I felt that I can help advance the OER agenda at the state level because I am knowledgeable and passionate about open education." That speaks volumes about why so many academic librarians are joining together at the state level to make a difference for the good of college students. 


\section{REFERENCES}

Allen, Nicole, Steven J. Bell, and Marilyn Billings. 2014. "Spreading the Word, Building a Community: Vision for a National Librarians OER Movement." Against the Grain 26 (5): 14-16. https://doi.org/10.7771/2380-176x.6842.

Bell, Steven J. 2012. "Coming in the Back Door: Leveraging Open Textbooks to Promote Scholarly Communications on Campus." Journal of Librarianship and Scholarly Communication 1 (1): 1-6. https://doi.org/10.7710/2162-3309.1040.

Bell, Steven J., and Joseph A. Salem Jr. 2017. "It's Up to the Librarians: Establishing a Statewide OER Initiative.” Pennsylvania Libraries: Research and Practice 5 (2): 77-82. https://doi .org/10.5195/palrap.2017.166.

Billings, Marilyn S., Sarah C. Hutton, Jay Schafer, Charles M. Schweik, and Matt Sheridan. 2012. "Open Educational Resources as Learning Materials: Prospects and Strategies for University Libraries.” Research Library Issues 280: 2-10. https://doi.org/10.29242/rli.280.2.

Jensen, Kristi, and Quill West. 2015. "Open Educational Resources and the Higher Education Environment: A Leadership Opportunity for Libraries." College Eं Research Libraries News 76 (4): 215-18. https://doi.org/10.5860/crln.76.4.9298.

Raymond, Courtney. 2018. "Rhode Island Making Progress with the Open Textbook Initiative." OpenStax, November 14. https://openstax.org/blog/rhode-island-making-progress-open -textbook-initiative.

Reed, Jason B., and Benjamin Jahre. 2019. "Reviewing the Current State of Library Support for Open Educational Resources." Collection Management 44 (2-4): 232-43. https://doi .org/10.1080/01462679.2019.1588181.

Seaman, Julia, and Jeffrey Seaman. 2020. Inflection Point: Educational Resources in Higher Education, 2019. Oakland: Bay View Analytics.

Student Public Interest Research Group. 2010. A Cover-to-Cover Solution: How Open Textbooks Are the Path to Textbook Affordability. Chicago: Student PIRGs.

Tomtas, Jystyna. 2019. “Officials Eye Ways to Stem the Rising Cost of Textbooks." Lewiston Tribune, September 27. https://lmtribune.com/northwest/officials-eye-ways-to-stem-the -rising-costs-of-textbooks/article_43e97aa4-5d3e-54fa-bff7-13559a57fa8b.html.

Vitez, Kaitlyn. 2020. Automatic Textbooks Billing: An Offer Students Can't Refuse? Denver: U.S. PIRG Education Fund.

Steven J. Bell is the associate university librarian for research and instructional services at Temple University, as well as chair of the Steering Committee for Affordable Learning Pennsylvania. He writes and speaks about academic librarianship, learning technologies, library leadership, higher education, open and affordable learning, design thinking, and user experience. He authored two regular columns for Library Journal Academic Newswire, "From the Bell Tower" and "Leading from the Library," from 2009 through 2019. He is coauthor of Academic Librarianship by Design and editor of Crucible Moments: Inspiring Library Leadership. He is currently an adjunct faculty member for the San Jose State University iSchool, where he teaches courses in design thinking and open education librarianship. Learn more at http://stevenbell.info. 